\title{
MANFAAT TEKNIK RELAKSASI MASSAGE MUSCULLUS TRAPEZIUS DENGAN AROMATERAPI MAWAR TERHADAP PERUBAHAN TEKANAN DARAH PADA IBU HAMIL
}

\author{
THE BENEFITS OF RELAXATION TECHNIQUES MASSAGE WITH \\ AROMATHERAPY TRAPEZIUS MUSCULLUS ROSES \\ TO CHANGES IN BLOOD PRESSURE \\ IN PREGNANT WOMEN
}

\author{
Ernawati $^{1)}$, Dian Safitri ${ }^{2)}$ \\ ${ }^{1) 2)}$ Program Studi Diploma III Kebidanan \\ Akademi Kebidanan Graha Mandiri Cilacap \\ Email: Ernawati@gmail.com
}

\begin{abstract}
ABSTRAK
Hipertensi dalam kehamilan merupakan 5-5\% penyulit kehamilan dan merupakan salah satu dari tiga penyebab tertinggi mortalitas dan morbiditas ibu bersalin di Indonesia. Terdapat 2 cara mengatasi hipertensi yang dapat dilakukan yaitu secara farmakologis dan non farmakologis. Beberapa jenis penanganan non farmakologi yang dapat dilakukan adalah akupresur (akupuntur tanpa jarum), terapi herbal, terapi jus, pijat (massage), yoga, aromaterapi, pernafasan dan relaksasi, meditasi, hypnosis dan perawatan dirumah. Tujuan penelitian ini adalah untuk mengetahui manfaat teknik relaksasi massage muscullus trapezius dengan aromaterapi mawar terhadap perubahan tekanan darah pada ibu hamil. Penelitian ini menggunakan rancangan kuantitatif dengan pendekatan cross sectional. Subyek dalam penelitian ini berjumlah 38 ibu hamil. Penelitian yang dilakukan di RSUD Hj. Anna Lasmanah Banjarnegara periode 4 Januari sampai 19 Februari 2016. Teknik pengambilan sampel dalam penelitian ini adalah Purposive Sampling. Data diperoleh melalui observasi langsung. Analisis data dilakukan dengan rumus t-test of related menggunakan pengolahan komputerisasi statiscal product and serve solution (SPSS 17). Hasil analisis data didapatkan nilai thitung sebesar 9,932 untuk tekanan darah sistol dan $t_{\text {hitung }}$ 6,173 untuk tekanan darah diastole. Jika $d f=38-1=37$ dan $\alpha=0,05$ maka didapatkan $t_{\text {tabel }} 2,042$. thitung $\leq t_{\text {tabel }}$ maka Ho diterima, Ha ditolak dan jika $t$ hitung $\geq t$ tabel maka Ho ditolak, Ha diterima. Dalam uji hipotesis didapatkan $t$ hitung $\geq t$ table (9,932>2,042) dan (6,173>2,042), maka dapat disimpulkan bahwa Ho ditolak dan Ha diterima. Maka terdapat manfaat teknik relaksasi massage muscullus trapezius dengan aromaterapi mawar terhadap perubahan tekanan darah pada ibu hamil.
\end{abstract}

Kata Kunci : Musculus Trapezius, Massage, Tekanan Darah, Aromaterapi

\begin{abstract}
Hypertension in pregnancy is 5-5\% complication of pregnancy and is one of the top three causes of maternal mortality and morbidity in Indonesia. There are two ways to overcome hypertension that can be done that pharmacological and non pharmacological. Some types of non-pharmacological treatment that can be done is acupressure (acupuncture without needles), herbal therapy, juice therapy, massage, yoga, aromatherapy, breathing and relaxation, meditation, hypnosis and home care. The purpose of this study was to determine the benefits of relaxation techniques muscullus trapezius massage with aromatherapy rose to changes in blood pressure in pregnant women. This study design was quantitative with cross sectional approach. Subjects in this study amounted to 38 pregnant women. Research conducted in hospitals Hj. Anna Lasmanah Banjarnegara period January 4 to February 19, 2016. The sampling technique in this research is purposive sampling. Data obtained through direct observation. Data were analyzed by t-test formula of related use of computerized processing and serve statiscal product solution (SPSS 17). The results of the analysis of data obtained tcount of 9.932 for systolic blood pressure and thitung 6.173 for diastolic blood pressure. If $d f=38-1=37$ and $\alpha=0.05$, obtained ttabel 2,042. $\leq$ thitung ttabel then Ho is accepted, Ha is rejected and if $t \geq t$ table then Ho is rejected, Ha accepted. In a hypothesis test obtained t arithmetic $\geq t$ table (9.932> 2.042) and (6.173> 2.042), it can be concluded that Ho is rejected and Ha accepted. This means that there are benefits of relaxation techniques muscullus trapezius massage with aromatherapy rose to changes in blood pressure in pregnant women.
\end{abstract}

Keywords: Musculus Trapezius, Massage, Blood Pressure, Aromatherapy 


\section{PENDAHULUAN}

Angka kematian ibu (AKI) merupakan salah satu indikator keberhasilan pelayanan kesehatan di suatu Negara. AKI menggambarkan jumlah wanita yang meninggal dari suatu penyebab kematian terkait dengan gangguan kehamilan atau penanganannya (tidak temasuk kecelakaan atau kasus insidentil) selama kehamilan, melahirkan dan dalam masa nifas (42 hari setelah melahirkan) tanpa memperhitungkan lama kehamilan per 100.00 kelahiran hidup.

Berdasarkan hasil Survei Demografi dan Kesehatan Indonesia tahun 2012 dibandingkan survei yang dilakukan pada tahun 2007 menunjukan bahwa tingkat kematian ibu mengalami peningkatan yang cukup tajam. Hasil estimasi pada tahun 2012, AKI mencapai 359 kematian per 100.000 kelahiran hidup sedangkan pada tahun 2007, AKI sebesar 228 kematian per 100.000 kelahiran hidup. Dapat disimpulkan bahwa AKI sepanjang tahun 2007 sampai tahun 2012 mengalami peningkatan sekitar 57\% (SDKI, 2012).

Hipertensi/ pre eklamsi menjadi salah satu penyebab terbesar angka kematian ibu di Provinsi Jawa Tengah. Hal ini didukung dengan data Dinas Kesehatan Provinsi Jawa Tengah tahun 2012 yang menunjukkan bahwa kematian ibu disebabkan oleh perdarahan 16,44\%, hipertensi/ pre eklamsi 35,26\%, infeksi $4,74 \%$, abortus $0,30 \%$ dan lain-lain $42,96 \%$ (Dinkes, 2015).

Menurut Ritu Jain (2011), penatalaksanaan hipertensi pada ibu hamil seringkali dilakukan secara farmakologis atau terapi obat. Terdapat 2 cara mengatasi hipertensi yang dapat dilakukan yaitu secara farmakologis dan non farmakologis. Beberapa jenis penanganan non farmakologi yang dapat dilakukan adalah akupresur (akupuntur tanpa jarum), terapi herbal, terapi jus, pijat (massage), yoga, aromaterapi, pernafasan dan relaksasi, meditasi, hypnosis dan perawatan dirumah.
Beberapa penelitian menunjukkan bahwa pendekatan non farmakologi dapat dilakukan pada penderita hipertensi. Dalam penelitian Olney (2005) mendapatkan hasil bahwa massage dapat menurunkan tekanan darah sistolik dan diastolik pada penderita hipertensi. Mekanisme massage ini dapat meningkatkan relaksasi dengan menurunkan aktivitas saraf simpatis dan meningkatkan aktivitas saraf parasimpatis sehingga terjadi vasodilatasi pembuluh darah dan penurunan tekanan darah.

\section{METODE PENELITIAN}

Penelitian ini dilaksanakan di Rumah Sakit Umum Daerah $\mathrm{Hj}$. Anna Lasmanah Banjarnegara. Waktu penelitian dilakukan pada November 2015 sampai dengan Maret 2016, sedangkan waktu pengambilan data penelitian dilaksanakan pada Januari sampai Februari 2016. Penelitian ini menggunakan rancangan kuantitatif dengan pendekatan cross sectional. Populasi dalam penelitian ini adalah seluruh ibu hamil yang memeriksakan kehamilannya di Rumah Sakit Umum Daerah $\mathrm{Hj}$. Anna Lasmanah Banjarnegara pada periode Januari sampai Februari 2016. Sampel dalam penelitian ini adalah seluruh ibu hamil yang memeriksakan kehamilannya di Rumah Sakit Umum Daerah $\mathrm{Hj}$. Anna Lasmanah Banjarnegara pada periode Januari sampai Februari 2016 yang memenuhi kriteria inklusi dan eksklusi responden penelitian ini. Teknik pengambilan sampel dalam penelitian ini adalah Purposive Sampling. Teknik yang digunakan sesuai dengan pendekatan penelitian (penelitian survey) yaitu untuk menganalisa rumusan masalah dan hipotesis dalam penelitian ini menggunakan rumus $T$-test of related untuk menguji hipotesis komparatif. Uji T-test of related dilakukan dengan menggunakan software SPSS. Uji T-test of related dilakukan untuk menguji hipotesis penelitian. 


\section{HASIL DAN PEMBAHASAN}

Analisi data yang digunakan dalam menguji hipotesis dengan data berbentuk rasio dilakukan penghitungan dengan menggunakan t-test related atau komparatif rata-rata dua sampel yang berkolerasi. Interpretasi data penelitian dalam penelitian ini adalah apabila $\mathrm{dk}=\mathrm{n}-1$ dan taraf kesalahan yang telah ditetapkan adalah 5\%, jika t hitung $>\mathrm{t}$ tabel maka Ho ditolak dan Ha diterima (Sugiyono, 2009). Hasil penghitungan dengan menggunakan komputerisasi dapat dilihat pada tabel di bawah ini.

Tabel Hasil Uji Paired sample t-test Tekanan Darah (Sistol) sebelum dan sesudah dilakukan teknik relaksasi massage muscullus trapezius dengan aromaterapi mawar

\begin{tabular}{llllcc}
\hline & Mean & $\begin{array}{l}\text { Std. } \\
\text { Deviation }\end{array}$ & f & $\begin{array}{l}\text { Sig. } \\
(\mathbf{2} \text {-tailed) }\end{array}$ \\
\hline $\begin{array}{l}\text { Sistol } \\
\text { sebelum - } \\
\text { sistol } \\
\text { setelah }\end{array}$ & 14.211 & 8.820 & .932 & 7 & 000 \\
\hline
\end{tabular}

Berdasarkan tabel diperoleh hasil $t_{\text {hitung }}$ sebesar 9,932. Menggunakan tingkat keyakinan $95 \% \quad(\alpha=0,05)$ dan derajat kebebasan $(\mathrm{df})=37$ diperoleh hasil $\mathrm{t}$ table sebesar 2,021.

Tabel Hasil Uji Paired sample t-test Tekanan Darah (Diastol) sebelum dan sesudah dilakukan teknik relaksasi massage muscullus trapezius dengan aromaterapi mawar.

\begin{tabular}{llllll}
\hline & Mean & $\begin{array}{c}\text { Std. } \\
\text { Deviation }\end{array}$ & t & f & $\begin{array}{c}\text { Sig. } \\
(2- \\
\text { tailed })\end{array}$ \\
\hline $\begin{array}{l}\text { Diastol } \\
\text { sebelum } \\
- \text { diastol } \\
\text { setelah }\end{array}$ & 9.289 & 9.276 & 6.173 & 37 & .000 \\
\hline
\end{tabular}

Berdasarkan tabel diperoleh hasil $t_{\text {hitung }}$ sebesar 6,173. Menggunakan tingkat keyakinan $95 \% \quad(\alpha=0,05)$ dan derajat kebebasan $(\mathrm{df})=37$ diperoleh hasil $\mathrm{t}$ table sebesar 2,021.

Berdasarkan data penelitian yang diperoleh di RSUD Hj. Anna Lasmanah Banjarnegara menunjukkan bahwa kejadian hipertensi pada ibu bersalin tidak hanya terjadi pada ibu dengan usia yang ekstrim diatas 35 tahun, namun dari $38 \mathrm{ibu}$ yang hipertensi sekitar $60 \%$ diantaranya adalah usia 20-35 tahun. Hal ini sesuai dengan Sarwono (2009) yang menyatakan bahwa umur adalah salat satu faktor resiko terjadinya hipertensi, pada kenyataannya ibu dengan umur 20-35 tahun banyak yang mengalami hipertensi.

Dalam data penelitian diperoleh hasil $71 \%$ ibu hamil yang mengalami kenaikan tekanan darah adalah pada umur kehamilan 37-40 minggu. Dari hal ini menunjukkan bahwa semakin mendekati proses persalinan ibu semakin dekat dengan kecemasan dan dapat menstimulus kontraksi pembuluh darah. Hal ini sesuai dengan Corwin (2011) yang menyatakan bahwa berbagai faktor seperti kecemasan dan ketakutan dapat mempengaruhi respon pembuluh darah terhadap rangsang vasokontriktor. Rangsangan pusat vasomotor dihantarkan dalam bentuk impuls yang bergerak ke bawah melalui saraf simpatis ke ganglia simpatis. Pada titik ini, neuron preganglion melepaskan asetilkolin, yang akan merangsang serabut saraf pasca ganglion ke pembuluh darah, dimana dengan dilepaskannya norepinefrin mengakibatkan konstriksi pembuluh darah sehingga terjadi peningkatan tekanan darah.

Penanganan kenaikan tekanan darah pada ibu hamil dapat dilakukan dengan cara non farmakologi. Hal ini sesuai dengan Muttaqin (2009) yang menyatakan bahwa penanganan hipertensi tidak selalu menggunakan obat-obatan, beberapa penelitian menunjukkan bahwa pendekatan non farmakologi dapat dilakukan pada penderita hipertensi yaitu meliputi; teknikteknik mengurangi stress, penurunan berat badan, olahraga atau latihan yang berefek meningkatkan lipoprotein berdensitas tinggi, dan relaksasi yang merupakan intervensi wajib yang harus dilakukan pada setiap terapi hipertensi.

Penanganan non farmakologi yang dilakukan pada penelitian ini untuk 
menurunkan tekann darah pada ibu hamil dengan hipertensi adalah dengan teknik relaksasi massage muscullus trapezius dengan aromaterapi mawar. Hal ini sesuai dengan Ritu Jain (2011) yang menyatakan bahwa penatalaksanaan hipertensi pada ibu hamil seringkali dilakukan secara farmakologis atau terapi obat. Terdapat 2 cara mengatasi hipertensi yang dapat dilakukan yaitu secara farmakologis dan non farmakologis. Beberapa jenis penanganan non farmakologi yang dapat dilakukan adalah akupresur (akupuntur tanpa jarum), terapi herbal, terapi jus, pijat (massage), yoga, aromaterapi, pernafasan dan relaksasi, meditasi, hypnosis dan perawatan dirumah.

$$
\text { Massage bermanfaat dalam }
$$

memperlancar peredaran darah dan getah bening serta memperlancar metabolisme dalam tubuh. Massage akan menstimulus kontraksi dinding kapiler untuk terjadi vasodilatasi pembuluh darah kapiler dan pembuluh getah bening sehingga aliran oksigen dalam darah meningkat dan pembuangan sisa-sisa metabolik semakin lancar. Massage dapat memberikan kesembuhan secara holistic dengan menimbulkan relaksasi pada pikiran, menghilangkan depresi dan perasaan panik melalui kontak khusus yang ditimbulkan dari sentuhan massage (Jurch, 2009).

Penatalaksanaan

pemberian aromaterapi mawar memberikan rasa rileks pada ibu hamil. Ibu hamil mengatakan merasa lebih nyaman dan tenang. Hal ini sesuai dengan pernyataan Sharma dalam Majidi dan Juanita (2013) yang mengatakan menghirup aromaterapi akan meningkatkan gelombang alfa di dalam otak untuk rileks, hal tersebut dapat menurunkan aktifitas vasokonstriksi pembuluh darah, aliran darah menjadi lancar sehingga menurunkan tekanan darah. Hal ini juga sesuai dengan penelitian Suprijati (2013) yang menunjukkan ada pengaruh yang signifikan antara pemberian aromaterapi dalam menurunkan kecemasan menghadapi persalinan.

\section{SIMPULAN}

Berdasarkan hasil analisis data didapatkan nilai $t_{\text {hitung sebesar 9,932 untuk }}$ tekanan darah sistol dan $t_{\text {hitung }} 6,173$ untuk tekanan darah diastole. Jika $\mathrm{df}=38-1=37$ dan $\alpha=0,05$ maka didapatkan $t_{\text {tabel }} 2,042$. $t_{\text {hitung }} \leq$ $t_{\text {tabel }}$ maka Ho diterima, Ha ditolak dan jika $t$ hitung $\geq \mathrm{t}$ tabel maka Ho ditolak, Ha diterima. Dalam uji hipotesis didapatkan $\mathrm{t}_{\text {hitung }} \geq \mathrm{t}_{\text {table }}$ $(9,932>2,042)$ dan $(6,173>2,042)$, maka dapat disimpulkan bahwa Ho ditolak dan $\mathrm{Ha}$ diterima. Artinya terdapat manfaat teknik relaksasi massage muscullus trapezius dengan aromaterapi mawar terhadap perubahan tekanan darah pada ibu hamil.

\section{DAFTAR PUSTAKA}

Andrews, P.W, \& Thomson, Jr.,J.A. 2009. The Bright Side of Being Blue: Depression as an Adaptation for Analyzing Complex Problem. Psychological Review

Charlton, J.Edmond. 2005. Muscle and Myofascial Pain. Seattle: IASP Press

Cunningham, F.G. 2005. Obstetri Williams. Jakarta: EGC

Depkes RI., 2015. Profil Kesehatan Indonesia. Jakarta

Jaelani. 2009. Aromaterapi. Jakarta: Pustaka Populer Obor

Jurch, S.E. 2009. Clinical Massage Therapy: Assessment and Therapy of Ortopedic Conditions. New York: McGraw-Hill

Kemenkes RI. 2014. Infodatin "Hipertensi". Jakarta: Pusat Data dan Informasi Kementerian Kesehatan RI

Kenia, Ni Made \& Taviyanda, Dian. 2013. Pengaruh Relaksasi (Aromaterapi 
Mawar) Terhadap Perubahan Tekanan Darah Pada Lansia Hipertensi. Kediri: STIKES RS Baptis

Kenny. 2008. The Effectiveness of Massage Therapy A Summary of EvidenceBased Research. Australia: RMIT University

Muttaqin, Arif. 2009. Buku Ajar Asuhan Keperawatan Klien dengan Gangguan Sistem Kardiovaskular dan Hematologi. Jakarta: Salemba Medika

Olney, CM. 2005. The Effect of Therapeutic Back Massage in Hypertensive Persons: a Preliminary Study. Biological Research for Nursing

Prawirohardjo, Sarwono. 2009. Ilmu Kebidanan. Jakarta: Yayasan Bina Pustaka Sarwono Prawirohardjo

Ritu Jain. 2011. Pengobatan Alternatif untuk Mengatasi Tekanan Darah. Jakarta: Gramedia

SDKI. 2014. Pusat Data dan Informasi. Jakarta: Kementerian Kesehatan Republik Indonesia

Sloane, Ethel. 2012. Anatomi dan Fisiologi Untuk Pemula. Jakarta: EGC

Tortora, G.J. dan Derrickson, B.H. 2012. Principles of Anatomy and Physiology Twelfth Edition. Asia: Wiley

Udjianti, Wajan Juni. 2011. Keperawatan Kardiovaskular. Jakarta: Salemba Medika

Wahyuni. 2014. Pengaruh Massase Ekstremitas Dengan Aromaterapi Lavender Terhadap Penurunan Tekanan Darah Pada Lansia
Hipertensi Di Kelurahan Grendeng Purwokerto. Purwokerto: Unsoed

Wikipedia. 2013. Otot Trapezius. Diakses dari https://id.wikipedia.org/wiki/Otot_tr apezius tanggal 1 Desember 2015

Lawton, G. 2003. Toward a neurophysiological understanding of manual therapy neuro-manual therapy. America 